\title{
Frequent monoallelic loss of D13S319 in multiple myeloma patients shown by interphase fluorescence in situ hybridization
}

\author{
$\mathrm{H} \mathrm{Chang}^{1}$, D Bouman ${ }^{3}, \mathrm{CF}$ Boerkoel $^{4}, \mathrm{AK}$ Stewart ${ }^{1}$ and JA Squire ${ }^{2,3}$ \\ ${ }^{1}$ Hematology Division, The Toronto Hospital; ${ }^{2}$ Departments of Medical Biophysics and Laboratory Medicine and Pathobiology, University of \\ Toronto; ${ }^{3}$ Cancer Cytogenetics Program and Ontario Cancer Institute; ${ }^{4}$ Division of Clinical Genetics, Hospital for Sick Children, Toronto, \\ Ontario, Canada
}

\begin{abstract}
Deletions or monosomy of chromosome 13 are frequent in multiple myeloma (MM). A candidate tumor suppressor gene might reside telomeric of the retinoblastoma gene $(R B)$ at band $13 q 14$ and to play a role in B cell neoplasm. The D13S319 locus, between $R B 1$ and $D 13 S 25$ loci at $13 q 14$ is the most commonly deleted marker in chronic lymphocytic leukemia (CLL) and nonHodgkin's lymphoma (NHL). We evaluated the D13S319 locus in $24 \mathrm{MM}$ cases by fluorescence in situ hybridization (FISH). We observed monosomy for D13S319 in $6 / 20(30 \%)$ MM patients with an apparently normal karyotype. As expected, in four karyotypically abnormal MM cases with partial or complete monosomy for chromosome 13, all of them had monoallelic loss of D13S319. Our results indicated that the loss of D13S319 is commonly found in MM, even at diagnosis, and is more frequent than predicted based on conventional cytogenetic analysis of metaphase spreads. This finding implicates a candidate tumor suppressor gene at $13 q 14$ in the pathogenesis of MM.

Keywords: tumor suppressor gene; deletion; chromosome 13; hematological malignancy; FISH; loss of heterozygosity
\end{abstract}

\section{Introduction}

Multiple myeloma $(\mathrm{MM})$ is a terminally differentiated clonal B cell tumor that usually has minimal proliferative activity. ${ }^{1}$ Conventional cytogenetic analysis of MM reveals abnormal karyotypes in 30-45\% of de novo cases, and $35-60 \%$ in previously treated and relapsing patients. ${ }^{2-4}$ Chromosome analysis is limited, however by the low number of metaphases. Cytogenetic analysis and measurement of DNA content of MM has demonstrated that almost all patients are cytogenetically abnormal. ${ }^{5}$ Although flow cytometric studies show a high frequency of DNA aneuploidy $(>80 \%)$ in $\mathrm{MM}$ and thereby suggest that chromosomal abnormalities may be important, ${ }^{6}$ the identity of the critical cytogenetic changes remains unknown.

Fluorescence in situ hybridization (FISH) circumvents the limitations of standard cytogenetics and allows for the detection of numerical and structural chromosomal abnormalities in both metaphase spreads and interphase nuclei. ${ }^{7}$ Thus FISH is an important and direct approach for assessing the incidence of chromosomal aberrations of MM. ${ }^{8-10}$

Deletions and monosomy of chromosome 13 are common cytogenetic abnormalities in MM and are associated with poor prognosis. ${ }^{11}$ Tricot et $\mathrm{al}^{11}$ showed that myeloma patients with either complete or partial deletion of chromosome 13 had significantly lower remission and survival rates. A candidate tumor suppressor gene on chromosome 13 has been recently localized to $13 q 14.3 . .^{12,13}$ The D13S319 locus, located

Correspondence: JA Squire, Division of Cellular and Molecular Biology, Ontario Cancer Institute, Princess Margaret Hospital, 610 University Avenue, Toronto, Ontario, M5G 2M9, Canada; Fax: 416 9462065

Received 4 February 1998; accepted 11 August 1998 between $R B 1$ gene and D13S25 (Figure 1), is frequently deleted in B-CLL and NHL. ${ }^{14,15}$ This suggests that the deletion of a tumor suppressor gene near D13S319, and distal to RB1, is a significant tumorigenic event in these malignancies. However, it is not known whether deletions in this vicinity of chromosome 13 also occur in MM or if such changes contribute to the pathogenesis of this disease. To evaluate the D13S319 region in MM, we used interphase FISH to analyze 24 previously characterized bone marrow cytogenetic specimens from MM patients.

\section{Materials and Methods}

\section{Patient samples}

Bone marrow samples from $24 \mathrm{MM}$ cases at different clinical stages (Table 1) were collected from our hematology outpatient clinic and transferred directly to the cytogenetics laboratory. Five cytogenetically normal bone marrow samples from a patient with anemia and a bone marrow transplant
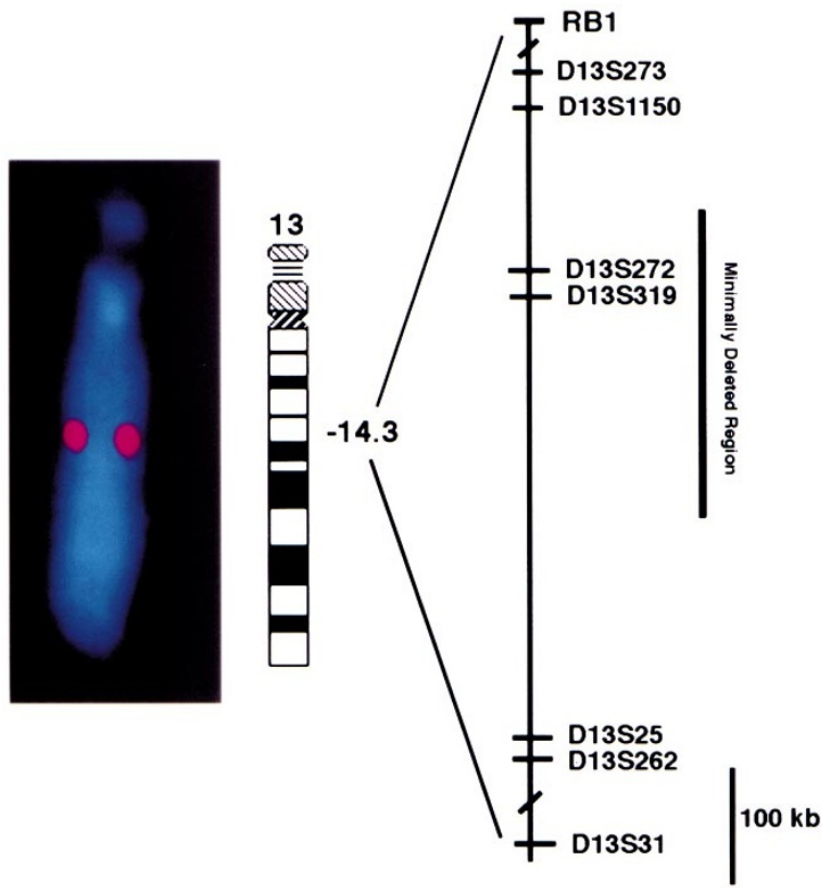

Figure 1 Hybridization of D13S319 DNA probe to chromosome 13 from a normal metaphase. Also shown is a map of the minimally deleted region in CLL and its relationship to D13S319 (not accurate to scale). 


\begin{tabular}{|c|c|c|c|c|c|c|c|}
\hline $\begin{array}{l}\text { Patient } \\
\text { No. }\end{array}$ & Age/Sex & Stage & Isotype & Prior TX & $\% B M$ & Karyotype & $\begin{array}{l}\text { FISH deletion } \\
\text { (D13S319)a }^{a}\end{array}$ \\
\hline 1 & $46 / \mathrm{M}$ & III & lgG k & Y & 60 & $46, X Y$ & $5 \%$ no \\
\hline 2 & $40 / \mathrm{M}$ & II & $\lg A \lambda$ & $\mathrm{N}$ & 15 & $46, X Y$ & $2 \%$ no \\
\hline 3 & $73 / \mathrm{M}$ & III & $\lambda$ chain & $\mathrm{N}$ & 40 & $46, X Y$ & $5 \%$ no \\
\hline 4 & $68 / \mathrm{M}$ & I & $\lg G \kappa$ & Y & 20 & $46, X Y$ & $6 \%$ no \\
\hline 5 & $48 / \mathrm{M}$ & III & $\lg G \kappa$ & Y & 30 & $46, X Y$ & $2 \%$ no \\
\hline 6 & $63 / \mathrm{M}$ & III & $\lg A \lambda$ & Y & 50 & 46, XY & $4 \%$ no \\
\hline 7 & $57 / F$ & I & $\lg G \lambda$ & $N$ & 40 & 46, XX & $7 \%$ no \\
\hline 8 & $54 / \mathrm{M}$ & III & $\lg G \kappa$ & NN & 60 & $46, X Y$ & $4 \%$ no \\
\hline 9 & $55 / F$ & III & $\lg G \kappa$ & & 20 & $46, X X$ & $3 \%$ no \\
\hline 10 & $43 / F$ & I & $\lg G \kappa$ & $\mathrm{N}$ & 40 & $46, X X$ & $4 \%$ no \\
\hline 11 & $62 / F$ & II & $\lg G \lambda$ & Y & 60 & $46, X X$ & $7 \%$ no \\
\hline 12 & $54 / \mathrm{M}$ & III & $\lg G \lambda$ & $\mathrm{N}$ & 30 & $46, X Y$ & $3 \%$ no \\
\hline 13 & $65 / \mathrm{M}$ & II & $\lg A \kappa$ & $\mathrm{N}$ & 10 & $46, X Y$ & $3 \%$ no \\
\hline 14 & $59 / \mathrm{M}$ & IIII & $\operatorname{lgG} \kappa$ & Y & 5 & $46, X Y$ & $4 \%$ no \\
\hline 15 & $66 / F$ & III & $\lambda$ chain & Y & 50 & 46, XX & $11 \%$ yes $^{b}$ \\
\hline 16 & $45 / F$ & II & $\lg G \lambda$ & $\mathrm{N}$ & 80 & 46, XX & $45 \%$ yes \\
\hline 17 & $56 / F$ & I & $\lg G \kappa$ & $N$ & 50 & $46, X X$ & $55 \%$ yes \\
\hline 18 & $54 / \mathrm{M}$ & II & $\lg G \kappa$ & $\mathrm{N}$ & 50 & $46, X Y$ & $14 \%$ yes \\
\hline 19 & $56 / F$ & III & $\lg G \kappa$ & $\mathrm{N}$ & 60 & 46, XX & $43 \%$ yes \\
\hline 20 & $57 / F$ & & $\lg A \kappa$ & $Y$ & 10 & $46, X X$ & $23 \%$ yes \\
\hline 21 & $72 / \mathrm{M}$ & III & $\lg G \kappa$ & Y & 60 & $\begin{array}{l}49, Y,-X, \operatorname{add}(1)(p 32),+? 2,+9,-10, \operatorname{add}(11)(p 15) \\
\operatorname{add}(12)(p 11),-13,-19,-20,+21,+22,+5 m a r(c p 4)\end{array}$ & $30 \%$ yes \\
\hline 22 & 48/F & I & $\lambda$ chain & $\mathrm{N}$ & 50 & $\begin{array}{l}\text { 46, X, -X, -6, ?del(13)(q12q22), ?del(21)(q24), add(16)(q24), } \\
\text { ?add(1)(q25), +mar(3) }\end{array}$ & $23 \%$ yes \\
\hline 23 & $45 / F$ & III & $\lg G \kappa$ & Y & 20 & $46, X X,+\operatorname{del}(1)(p 13),-13, \operatorname{add}(18)(p 11)$ & $85 \%$ yes \\
\hline 24 & $57 / F$ & II & IgG & Y & 90 & $\begin{array}{l}\text { 43, } X X, \text { del(3), t(3:8) }(q 13 ; q 11), \operatorname{add}(5)(p 15),-7,-8,-9, \\
\operatorname{add}(12)(p 11),-13, \operatorname{add}(19)(q 13),-19,-20,+3 \operatorname{mar}(c p 5) / 46, \\
X X(13)\end{array}$ & $17 \%$ yes \\
\hline
\end{tabular}

aPercentage of interphase nuclei with one signal and interpretation of findings where 'no' indicates absence of deletion, 'yes' indicates a deletion is present.

bThis value was determined to be statistically significant in comparison to the control series $(P<0.005)$.

recipient were used as controls. Samples were processed for cytogenetic and FISH analysis.

\section{G-banding analysis}

Both direct (uncultured) and 24-h cultures were harvested using standard protocols. ${ }^{16}$ Metaphases were analyzed using GTG method. ISCN criteria were used to define abnormal clones. ${ }^{17}$ A sample was classified as cytogenetically abnormal if at least one abnormal clone was characterized with a minimum of 10 cells analyzed. The direct (uncultured) specimen was used first and the 24-h culture used only if the direct specimen was cytogenetically normal or if an inadequate number of metaphases were obtained from the direct specimen.

\section{FISH}

Interphase FISH was performed using standard methods. ${ }^{7}$ Slides made from the bone marrow samples were prewarmed in $2 \times \mathrm{SSC} \mathrm{pH} 7.0$ at $37^{\circ} \mathrm{C}$ for $30 \mathrm{~min}$. The slides were then dehydrated in an ethanol series, and denatured in a solution of $70 \%$ formamide in $2 \times \mathrm{SSC}$ at $70^{\circ} \mathrm{C}$. Slides were hybridized to a commercially available probe at $37^{\circ} \mathrm{C}$ in a humidified chamber overnight. The probe was LSI D13S319 (13q14.3), a DNA probe directly labeled with spectrum orange provided by Vysis (Dowers Grove, IL, USA). The slides were then washed with $0.4 \times \mathrm{SSC}, 0.3 \% \mathrm{NP}-40$ at $72^{\circ} \mathrm{C}$ and with $2 \times$ SSC, $0.1 \%$ NP-40. After counterstaining with 4,6 diamino-2phenylindole (DAPI), the slides were evaluated on an epi-fluorescence microscope. Slides were coded and scored by two independent observers to derive the frequencies of monosomy. Nuclei with only one signal present were scored as monosomic for D13S319. In total, hybridization signals were enumerated in 600 interphase nuclei for each specimen.

\section{Results and discussion}

The clinical, immunoglobulin isotype and cytogenetic data of MM patients included in the study are summarized in Table 1. They were of different clinical stages with various degrees of marrow plasmacytosis. Thirteen $(50 \%)$ patients were newly diagnosed with $\mathrm{MM}$ and had no prior chemotherapy; the remainder had relapsing or progressive disease with at least 3 months of chemotherapy. Seventeen patients had IgG myeloma, four IgA myeloma, and three light chain disease. By conventional cytogenetic analysis 20 patients had normal karyotypes and four had complete or partial monosomy for chromosome 13 in addition to other chromosomal abnormalities (Table 1).

The commercially available genomic probe used to detect the presence or absence of the D13S319 locus in interphase nuclei was a 110-140 kb cosmid contig (Vysis). As shown in 
Figure 1, the minimally deleted region in CLL is less than $300 \mathrm{~kb}$ and has been mapped to band $13 \mathrm{q} 14.3$ approximately $100 \mathrm{~kb}$ distal to $\mathrm{RBI}^{18}{ }^{18}$ This region includes D13S319 and D13S272. FISH analysis with D13S319 probe was performed on five control samples and $24 \mathrm{MM}$ patients (Figure 2). On average, $4.2 \%$ of control nuclei had one signal, presumably resulting from close juxtaposition of independent signals, or inefficient hybridization in those nuclei. ${ }^{7}$ This level of background nuclei with one signal is consistent with the expected hybridization efficiencies for this directly labeled commercial probe (information provided by $\mathrm{Vysis}$ ), and for clinical applications of interphase FISH. ${ }^{19}$ A deletion was noted when samples exhibited a greater frequency of interphase nuclei with one D13S319 signal. In all studied cases, less than $0.5 \%$ of nuclei had none or three signals. None of the cases included in the study exhibited 'patchy hybridization' on microscope slides, and both the intensity and FISH signal diameter were uniform in all nuclei indicating that the target interphase chromatin was of optimal quality.

Samples that scored positive for a deletion ranging from 11$85 \%$ of nuclei. Patients $15-20$ had a deletion by interphase FISH despite having a normal karyotype by conventional metaphase analysis. All patients with a cytogenetic monosomy or deletion or chromosome 13 (patients 21-24 in Table 1) in their karyotype also scored positive for a deletion of D13S319 by interphase FISH analysis. However, the percentage of interphase nuclei with a deletion in these samples ranged from
17-85\%. Our findings indicate that the mitotically active representative of the overall cytogenetic composition. ${ }^{19}$ Deviations between metaphase and interphase FISH results suggest that the patient samples often contain a mixture or normal and $\mathrm{MM}$ cells, and that one component may be mitotically more active than the other. Alternatively, in some cases of MM it is possible that the proportion of nuclei with one D13S319 signal represents loss of 13 as a secondary change within a neoplastic clone. More detailed studies are required to characterize these observations further.

The presence of chromosome 13 deletions both early and late in the disease course, strongly suggests the involvement of a tumor suppressor gene in the evolution of $\mathrm{MM}^{1}{ }^{1}$ similar to the observations in CLL. ${ }^{15}$ Previous studies have shown that the most common monosomy in $\mathrm{MM}$ involves chromosome $13(14-43 \%){ }^{8,11}$ In this report, we investigated the monoallelic loss of the D13S319 locus on chromosome 13 in MM patients. Using FISH analysis of MM bone marrow cells, our results demonstrated that loss of the region identified by D13S319 was common (30\%) in MM patients who appeared karyotypically normal for $13 q 14$. Since our study focused on MM cases with normal karyotypes, the total incidence of monoallelic deletion of D13S319 in MM is therefore likely to be greater than $30 \%$. To our knowledge, this is the first report of such frequent loss of the $13 q 14.3$ region.

We examined several clinical and prognostic factors with
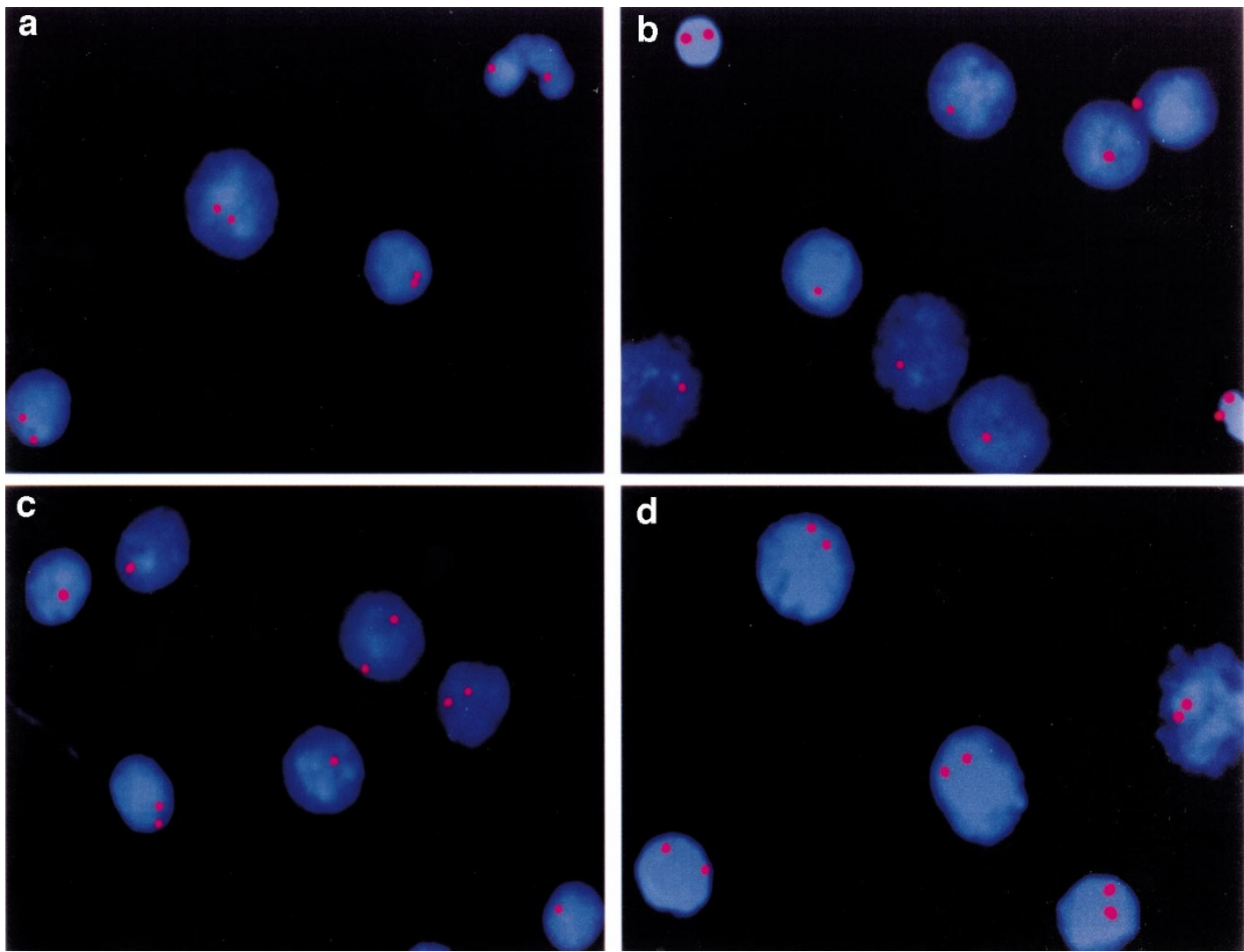

Figure 2 Analysis of the D13S319 locus by FISH. (a) Control sample showing two signals for D13S319 in the nuclei. (b) MM case with monosomy for chromosome 13 showing a deletion of D13S319 locus (one signal in most of cells). (c) About half of the cells showing one signal in a MM case with normal karyotype. (d) D13S319 was retained (two signals) in a MM case with normal karyotype. 
respect to the D13S319 deletion in MM cases studied to determine whether any clinical trend was apparent. There was no apparent relationship to tumor stage, immunoglobulin isotype, hemoglobin, serum beta- 2 microglobulin level or patient age. A more extensive clinical correlative study would be required to determine whether this deletion was associated with other clinical parameters. Monosomy for D13S319 was observed with similar frequency in patients with or without extensive prior treatment, suggesting that the loss of the D13S319 locus in these patients is a relatively early event in the pathogenesis of MM, and was not induced by chemotherapy.

Allelic loss is thought to mark the location of the tumor suppressor gene involved in the pathogenesis and progression of human malignancies. ${ }^{20}$ Studies on B-CLL by Liu et $\mathrm{a}^{14}$ revealed chromosome 13 deletions in $44 \%$ of the observed cases. The most commonly deleted region was D13S319, and the smallest region of overlap for the deletions was between RB1 and the D13S25 loci. A more refined localization was performed by others who indicated that at least $40 \%$ of B-CLL cases showed a deletion in this region. ${ }^{15}$ It has been proposed that a candidate tumor suppressor gene located in the vicinity of D13S319 is involved in the malignant transformation of BCLL, and our studies suggest this same region may also be involved in MM.

The tumor suppressor gene $R B 1$ has been previously assigned to the $13 \mathrm{q} 14 .{ }^{21}$ Loss of the $R B 1$ gene function is involved in the development of retinoblastoma and other solid tumors. ${ }^{20-22}$ Monoallelic RB1 gene deletion by FISH analysis was detected in at least $30 \%$ of $\mathrm{B}^{-\mathrm{CLL}^{23}}$ and $50 \%$ of $\mathrm{MM}$ patients. ${ }^{24}$ In B-CLL, a substantial number of patients had homozygous of hemizygous deletions of the $13 q 14.3$ region when D13S25 was used as a marker, but retained the intact $R B 1$ gene. $^{25}$ In our MM cases, it is not clear if $R B 1$ is also deleted in those patients with loss of D13S319 locus. However, it is conceivable that deletions of $R B 1$ and the putative tumor suppressor gene at $13 q 14.3$ may both contribute to the pathogenesis of B-CLL and MM. It is well established that allelic loss in this region of chromosome 13 can also be identified by loss of heterozygosity ( $\mathrm{LOH}$ ) analysis (reviewed in Ref. 19). Diverse chromosomal mechanisms lead to $\mathrm{LOH}$ and often generate two genetically identical chromosome 13s in a tumor. In such cases, signal loss will not be detectable by interphase FISH. Future studies should address the incidence of D13S319 deletion in a larger group of MM patients using FISH together with $\mathrm{LOH}$ analysis, and evaluate the prognostic significance of such changes.

\section{Acknowledgements}

This work was supported by the National Cancer Institute of Canada with funds from the Canadian Cancer Society.

\section{References}

1 Hallek M, Bergsagel PL, Anderson KC. Multiple myeloma: increasing evidence for a multistep transformation process. Blood 1998; 91: 3-21.

2 Dewald GW, Kyle RA, Hicks GA, Greipp PR. The clinical significance of cytogenetic studies in 100 patients with multiple myeloma, plasma cell leukemia, or amyloidosis. Blood 1985; 66 380-389.

3 Gould J, Alexanian R, Goodace A, Pathak S, Hecht B, Barlogie
B. Plasma cell karyotype in multiple myeloma. Blood 1988; 71 453-456.

4 Sawyer JR, Waldron JA, Jagannath S, Barlogie B. Cytogenetic findings in 200 patients with mutiple myeloma. Cancer Genet Cytogenet 1995; 82: 41-49.

5 Zandecki M, Lai IL, Facon T. Multiple myeloma: almost all patients are cytogenetically abnormal. Br J Haematol 1996; 94: 217-227.

6 Latrielle J, Barlogie B, Gohde W, Johnston D, Drewinko B, Alexanian R. Cellular DNA content as a marker of human multiple myeloma. Blood 1980; 55: 403-408.

7 Dracopoli NC. Current Protocols in Human Genetics. John Wiley: New York, 1995.

8 Tabernero D, San Miguel JF, Garcia-Sanz R, Najera L, Garcia-Isidoro M, Perez-Simon JA, Gonzalez M, Wiegant J, Raap AK, Orfao A. Incidence of chromosome numerical changes in multiple myeloma. Am J Pathol 1996; 149: 153-161.

9 Drach J, Angerler J, Schuster J, Rothermundt C, Thalhammer R, Haas OA, Jager U, Fiegl M, Geissler K, Ludwig $H$, Huber $H$. Interphase fluorescence in situ hybridization identifies chromosomal abnormalities in plasma cells from patients with monoclonal gammopathy of undetermined significance. Blood 1995; 86: $3915-3921$

10 Flactif M, Zandecki M, Lai JL, Bernardi F, Obein V, Banters F, Facon $\mathrm{T}$. Interphase fluorescence in situ hybridization (FISH) as a powerful tool for the detection of aneuploidy in multiple myeloma. Leukemia 1995; 9: 2109-2114.

11 Tricot G, Barlogie B, Jagannath S, Bracy D, Mattox S, Vesole D, Naucke S, Sawyer JR. Poor prognosis in multiple myeloma is associated only with partial or complete deletions of chromosome 13 or abnormalities involving $11 \mathrm{q}$ and not with other karyotype abnormalities. Blood 1995; 86: 4250-4256.

12 Brown AG, Ross FM, Eimer MD, Steel CM, Weir-Thompson EM. Evidence for a new tumor suppressor locus (DBM) in human $B$ cell neoplasia telomeric to the retinoblastoma gene. Nat Genet 1993; 3: 67-72.

13 Liu Y, Szekely L, Grander D, Soderhall S, Juliusson G, Gahrton G, Linder S, Einhorn S. Chronic lymphocytic leukemia cells with allelic deletions at $13 q^{14}$ commonly have one intact $R B 1$ gene: evidence for a role of an adjacent locus. Proc Natl Acad Sci USA 1993; 90: 8697-8701.

14 Liu $Y$, Hermanson M, Grander D, Merup M, Wu X, Heyman M, Rasool O, Juliusson G, Gahrton G, Detlofsson R, Nikiforova N, Buys C, Soderhall S, Yankovsky N, Zabarovsky E, Einhorn S. 13a deletions in lymphoid malignancies. Blood 1995; 86: 1911-1915.

15 Bullrich F, Veronese ML, Kitada S, Jurlander J, Caligiuri MA, Reed JC, Croce CM. Minimal region of loss at 13q14 in B cell chronic lymphocytic leukemia. Blood 1996; 88: 3109-3115.

16 Barch M (ed). The AGT Cytogenetic Laboratory Manual, 2nd edn, New York, 1997.

17 ISCN (1995). International System for Human Cytogenetic Nomenclature. Mitelman F (ed). S Karger: New York, 1995.

18 Kalachikov S, Migliazza A, Cayanis E, Fracchiolla NS, Bonaldo MF, Lawton L, Jelenc P, Ye X, Qu X, Chien M, Hauptschein R, Gaidano G, Vitolo U, Saglio G, Resegotti L, Brodjansky V, Yankovsky N, Zhang P, Soares MB, Russo J, Edelman IS, Efstratiadis A, Dalla-Favera R, Fischer SG. Cloning and gene mapping of the chromosome 13 q14 region deleted in chronic lymphocytic leukemia. Genomics 1997; 42: 369-377.

19 Cuneo A, Bigoni R, Roberti MG, Bardi A, Balsamo R, Piva N, Castoldi G. Detection of numerical aberrations in hematologic neoplasias by fluorescence in situ hybridization (review). Haematologica 1997; 82: 85-90.

20 Cavenee WK, White R. The genetic basis of cancer. Scientific American 1995; 272: 72-81.

21 Friend SH, Bernards R, Rogelj S, Weinberg RA, Rapaport JM, Albert DM, Dryja TP. A human DNA segment with properties of the gene that predisposes to retinoblastoma and osteosarcoma. Nature 1986; 323: 643-646.

22 Cance WG, Brennan MF, Dudas ME, Huang CM, Cordon-Cardo C. Altered expression of the retinoblastoma gene product in human sarcomas. New Engl J Med 1990; 323: 1457-1462.

23 Stilgenbauer S, Dohner H, Bulgay-Morschel M, Weitz S, Bentz $M$, Lichter P. High frequency of monoallelic retinoblastoma gene deletion in B-CLL chronic lymphoid leukemia shown by interphase cytogenetics. Blood 1993; 81: 2118-2124. 


\section{Monoallelic loss of D13S319 in MM}

24 Dao DD, Sawyer JR, Epstein J, Hoover RG, Barlogie B, Tricot G. Deletion of the retinoblastoma gene in multiple myeloma. Leukemia 1994; 8: 1280-1284.

25 Stilgenbauer S, Leupolt E, Ohl S, Wei G, Schroder M, Fischer K,
Bentz $\mathrm{M}$, Lichter $\mathrm{P}$, Dohner $\mathrm{H}$. Heterogeneity of deletions involving RB-1 and the D13S25 locus in B cell chronic lymphocytic leukemia revealed by fluorescence in situ hybridization. Cancer Res 1995; 55: 3475-3477. 